\title{
Factors Associated with Insomnia among the Elderly in a Korean Rural Community
}

\author{
Woo Jung Kim ${ }^{1,2}$, Won-tak Joo ${ }^{3}$, Jiwon Baek ${ }^{3}$, Sung Yun Sohn' ${ }^{2,4}$, Kee Namkoong ${ }^{2,4}$, Yoosik Youm³, \\ Hyeon Chang Kim ${ }^{5}$, Yeong-Ran Park ${ }^{6}$, Sang Hui Chu', and Eun Lee ${ }^{2,4} \bowtie$ \\ ${ }^{1}$ Department of Psychiatry, Seonam University College of Medicine, Myongji Hospital, Goyang, Republic of Korea \\ ${ }^{2}$ Institute of Behavioral Science in Medicine, Yonsei University College of Medicine, Seoul, Republic of Korea \\ ${ }^{3}$ Department of Sociology, Yonsei University, Seoul, Republic of Korea \\ ${ }^{4}$ Department of Psychiatry, Yonsei University College of Medicine, Seoul, Republic of Korea \\ ${ }^{5}$ Department of Preventive Medicine, Yonsei University College of Medicine, Seoul, Republic of Korea \\ ${ }^{6}$ Division of Silver Industry, Kangnam University, Yongin, Republic of Korea \\ ${ }^{7}$ Department of Clinical Nursing Science, Yonsei University, Seoul, Republic of Korea
}

Objective Sleep disturbance is common in the elderly, which is result from multi-factorial causes encompassing socio-demographic, behavioral, and clinical factors. We aimed to identify factors associated with insomnia among the elderly in a rural community in South Korea, a country with a rapidly growing aged population.

Methods This cross-sectional study used the data from the second wave of the Korean Social life, Health and Ageing Project, which is a cohort study of individuals living in a typical rural community in South Korea. Socio-demographic, behavioral, and clinical characteristics were obtained through face-to-face interviews. Various factors suspected to be associated with insomnia were compared between elderly participants with and without insomnia, and multiple logistic regression analyses were conducted to identify independent risk factors for insomnia.

Results We found that $32.4 \%$ of 509 participants $(72.8 \pm 7.7$ years old) had insomnia. Female sex [odds ratio $(\mathrm{OR})=2.19$ ], low education level $(\mathrm{OR}=2.44)$, current smoking $(\mathrm{OR}=2.26)$, number of chronic diseases $(\mathrm{OR}=2.21$ for $2-3$ chronic diseases; $\mathrm{OR}=2.06$ for 4 or more chronic diseases), and depression $(\mathrm{OR}=2.53)$ were independently associated with insomnia.

Conclusion We found that sex, education, chronic disease, and depression independently increase the risk of insomnia of the elderly in a Korean rural community. To overcome the elderly's insomnia, interventions should target modifiable factors such as depression. To promote active aging, longitudinal studies of factors associated with insomnia among the elderly should be performed in different regions and communities.

Psychiatry Investig 2017;14(4):400-406

Key Words Insomnia, Aged, Depression, Rural population, Republic of Korea.

\section{INTRODUCTION}

According to the World Health Organization, active aging is the process of optimizing opportunities for health, participation, and security as people age. ${ }^{1}$ One of the most important determinants of active aging is health, which includes both

Received: May 1, 2016 Revised: June 12, 2016

Accepted: June 18, 2016 Available online: February 27, 2017

$\triangle$ Correspondence: Eun Lee, MD, PhD

Department of Psychiatry, Yonsei University College of Medicine, 50-1 Yonsei-ro, Seodaemun-gu, Seoul 03722, Republic of Korea

Tel: +82-2-2228-1620, Fax: +82-2-313-0891, E-mail: leeeun@yuhs.ac

(a) This is an Open Access article distributed under the terms of the Creative Commons Attribution Non-Commercial License (http://creativecommons.org/licenses/by$\mathrm{nc} / 4.0$ ) which permits unrestricted non-commercial use, distribution, and reproduction in any medium, provided the original work is properly cited. physical and mental health. The concept of active aging is getting attention from researchers and policy makers, who are interested in understanding modifiable factors, such as sleep, that can improve and promote the health of aging populations.

With the rapid growth of the aging population in South Korea, ${ }^{2}$ sleep problems are receiving more attention. The number of South Korean people who underwent treatment for sleep disorders was increased by $16 \%$ from 2012 to $2014 .{ }^{3}$ People over 60 years of age made up the largest portion of this treated population (45\%), and their growth rate (25\%) was the highest in all age group. The most commonly diagnosed sleep disorder was insomnia (67\%). Despite the growing interest in sleep among older adults in Korea, specific data and strategies for preventing or treating sleep disorders are lack- 
ing. Although sleep duration decreases with age, and insomnia is common in older adults, insufficient or unsatisfactory sleep is not a normal part of aging. ${ }^{4}$

Insomnia is not only a cause of heterogeneous health conditions but also an outcome of many different factors. ${ }^{5}$ Persistent insomnia affects both physical and mental health. ${ }^{4,6}$ Insomnia increases risks of mortality, falling-down, ${ }^{8}$ depression, ${ }^{6}$ and decreases a quality of life in elderly individuals. Moreover, treating insomnia can lower the risk of medical disease..$^{10}$ Insomnia is influenced by socio-demographic characteristics, physical and mental health status, and other sleep-related symptoms. ${ }^{4,5}$ In Korea, there are several studies about sleep disorders in older adults; ${ }^{11-17}$ they focused mostly on the urban elderly. Sleep patterns, chronotype, and light exposure are different between the urban and rural population. ${ }^{18}$ In addition, due to inequalities in socio-economic status and accessibility to medical services between rural and urban areas, ${ }^{19}$ it is also important to investigate contributing factors to insomnia amongthe rural elderly.

Considering the need for health-related prevention policies for aged population, it is necessary to carry out a rural community-based study of insomnia including a diverse array of sleep-related factors. Therefore, we aimed to identify factors associated with insomnia among older adults in a Korean rural community to form a basis for promoting good sleep active aging of elderly in dividuals.

\section{METHODS}

\section{Study population}

This study used data from the Korean Social life, Health and Ageing Project (KSHAP), which is an ongoing communitybased cohort study. The target population of the KSHAP is people aged 60 years or older living within one township in Korea ("Y"-myeon, Ganghwa-gun, Incheon, Korea). This township is a typical rural area in Korea, where farming is the main industry. The data collection procedure has been described in detail elsewhere. ${ }^{20}$ During the second wave of the KSHAP (September 2012-August 2013), 509 participants completed a questionnaire survey. To examine insomnia and its correlates, we used cross-sectional data from this second wave, which included more number of sleep-related variables than ones of the other waves of the KSHAP. All participants provided written informed consent. The Institutional Review Board of Yonsei University approved this study.

\section{Measurement}

Through the face-to-face interviews, we obtained information on socio-demographic, behavioral, and clinical variables. Considering that participants lived in a rural area, we also asked about difficulty in accessing medical services during the last year. The questionnaire included items about difficulty with sleep initiation or maintenance, average sleep duration during the last year, and presence of snoring. We considered insomnia as being present if the respondent reported difficulty in sleep initiation or maintenance. If the answer to the question "Have you heard that you snore?" was "yes", then the following question was asked to identify snoring with apnea: "Have you heard from your bed partner that you stop breathing with snoring?" Because the first screening question for snoring was too inclusive, we used snoring with apnea as a variable instead of the presence of snoring.

We also collected participant histories of the following diseases: hypertension, diabetes mellitus, hyperlipidemia, arthritis, osteoporosis, cancer, stroke, myocardial infarction (or angina), tuberculosis, asthma, hepatitis B, and urination disorder (i.e., urinary incontinence for both sex and benign prostate hyperplasia for males). Interference by pain was measured with the following question from the SF-12 Health Survey version $2^{21}$ : "How much did pain interfere with your normal work?" We considered the answer of "not at all" and "a little bit" as negative answers and "moderately", "quite a bit", and "extremely" as positive answers. Depression was defined as a score of $\geq 10$ on the Geriatric Depression Scale-Short Form (15 items). ${ }^{22}$ Cognitive impairment was defined as a score of $\leq 23$ on the Mini-Mental State Examination. ${ }^{23}$ Subjective degree of physical activity was classified into two categories of the activity level: none to low versus moderate to high. We regarded moderate activity as in regular, even if light, exercise.

\section{Statistical analyses}

The following suspected associated factors for insomnia were compared between participants with and without insomnia using independent $\mathrm{t}$-tests and chi-square tests when appropriate: age, sex, education level, perceived economic status, marital status, smoking status, alcohol intake, difficulty of access to medical services, number of chronic diseases, presence of urination disorder, interference by pain, presence of depression and cognitive impairment, and physical activity level. Sleep duration and snoring with apnea were also compared between groups. There were no missing data for any of the variables.

To examine which factors are associated with insomnia, we performed two regression analyses: first, using all variables except sleep duration and snoring with apnea (model 1), and second, using all variables including sleep duration and snoring with apnea (model 2). Even if not significantly different in the descriptive analyses, all of the above-mentioned variables were entered into the multiple logistic regression models for insomnia because we assumed that each variable 
Table 1. Participant characteristics depending on the presence of insomnia

\begin{tabular}{|c|c|c|c|c|}
\hline Variables & Total $(\mathrm{N}=509)$ & No insomnia $(\mathrm{N}=344)$ & Insomnia $(\mathrm{N}=165)$ & $\mathrm{p}$ value \\
\hline Age (years), mean \pm SD & $72.8 \pm 7.7$ & $72.2 \pm 7.5$ & $74.1 \pm 7.9$ & 0.010 \\
\hline Sex, $N(\%)$ & & & & $<0.001$ \\
\hline Male & $221(43.4)$ & $176(51.2)$ & $45(27.3)$ & \\
\hline Female & $288(56.6)$ & $168(48.8)$ & $120(72.7)$ & \\
\hline Education level, $\mathrm{N}(\%)$ & & & & $<0.001$ \\
\hline$\geq 7$ years & $152(29.9)$ & $127(36.9)$ & $25(15.2)$ & \\
\hline $0-6$ years & $357(70.1)$ & $217(63.1)$ & $140(84.8)$ & \\
\hline Perceived economic status, N (\%) & & & & 0.946 \\
\hline Fair & $365(71.7)$ & $118(71.5)$ & $247(71.8)$ & \\
\hline Poor & $144(28.3)$ & $47(28.5)$ & $97(28.2)$ & \\
\hline Marital status, $\mathrm{N}(\%)$ & & & & $<0.001$ \\
\hline Married & $374(73.5)$ & $270(78.5)$ & $104(63.0)$ & \\
\hline Unmarried/divorced/widowed & $135(26.5)$ & $74(21.5)$ & $61(37.0)$ & \\
\hline Current Smoking, N (\%) & & & & 0.644 \\
\hline No & $455(89.4)$ & $306(89.0)$ & $149(90.3)$ & \\
\hline Yes & $54(10.6)$ & $38(11.0)$ & $16(9.7)$ & \\
\hline Alcohol drinking $\geq 1$ /week, $\mathrm{N}(\%)$ & & & & 0.001 \\
\hline No & $399(78.4)$ & $255(74.1)$ & $144(87.3)$ & \\
\hline Yes & $110(21.6)$ & $89(25.9)$ & $21(12.7)$ & \\
\hline Difficulty of access to medical services, $\mathrm{N}$ (\%) & & & & 0.440 \\
\hline No & $478(93.9)$ & $325(94.5)$ & $153(92.7)$ & \\
\hline Yes & $31(6.1)$ & $19(5.5)$ & $12(7.3)$ & \\
\hline Number of chronic diseases, $\mathrm{N}(\%)^{*}$ & & & & $<0.001$ \\
\hline $0-1$ & $214(42.0)$ & $168(48.8)$ & $46(27.9)$ & \\
\hline $2-3$ & $237(46.6)$ & $141(41.0)$ & $96(58.2)$ & \\
\hline 4 or more & $58(11.4)$ & $35(10.2)$ & $23(13.9)$ & \\
\hline Urination disorder, $\mathrm{N}(\%)^{\dagger}$ & & & & 0.432 \\
\hline No & $420(82.5)$ & $287(83.4)$ & $133(80.6)$ & \\
\hline Yes & $89(17.5)$ & $57(16.6)$ & $32(19.4)$ & \\
\hline Interference by pain, $\mathrm{N}(\%)$ & & & & 0.079 \\
\hline No & $397(78.0)$ & $276(80.2)$ & $121(73.3)$ & \\
\hline Yes & $112(22.0)$ & $68(19.8)$ & $44(26.7)$ & \\
\hline Depression, $\mathrm{N}(\%)^{\ddagger}$ & & & & $<0.001$ \\
\hline No & $452(88.8)$ & $318(92.4)$ & $134(81.2)$ & \\
\hline Yes & $57(11.2)$ & $26(7.6)$ & $31(18.8)$ & \\
\hline Cognitive impairment, $\mathrm{N}(\%)^{\S}$ & & & & 0.099 \\
\hline No & $340(66.8)$ & $238(69.2)$ & $102(61.8)$ & \\
\hline Yes & $169(33.2)$ & $106(30.8)$ & $63(38.2)$ & \\
\hline Physical activity level, N (\%) & & & & 0.355 \\
\hline Moderate-high & $323(63.5)$ & $223(64.8)$ & $100(60.6)$ & \\
\hline None-low & $186(36.5)$ & $121(35.2)$ & $65(39.4)$ & \\
\hline Sleep duration (hours), mean \pm SD & $8.3 \pm 1.5$ & $8.4 \pm 1.3$ & $8.1 \pm 1.9$ & 0.027 \\
\hline Snoring with apnea, N (\%) & & & & 0.984 \\
\hline No & $478(93.9)$ & $323(93.9)$ & $155(93.9)$ & \\
\hline Yes & $31(6.1)$ & $21(6.1)$ & $10(6.1)$ & \\
\hline
\end{tabular}

*includes hypertension, diabetes mellitus, hyperlipidemia, arthritis, osteoporosis, cancer, stroke, myocardial infarction (or angina), tuberculosis, asthma, and hepatitis, tincludes urinary incontinence and benign prostate hyperplasia, ${ }^{\ddagger}$ defined by $\geq 10$ of the Geriatric Depression ScaleShort Form (15-item) scores, §defined by $\leq 23$ of the Mini-Mental State Examination scores 
WJ Kim et al.

Table 2. Multiple logistic regression models of factors associated with insomnia among the Korean rural elderly

\begin{tabular}{|c|c|c|c|c|}
\hline \multirow{2}{*}{ Variables } & \multicolumn{2}{|c|}{ Model 1} & \multicolumn{2}{|c|}{ Model 2} \\
\hline & OR $(95 \% \mathrm{CI})^{*}$ & $\mathrm{p}$ value & OR $(95 \% \mathrm{CI})^{*}$ & $\mathrm{p}$ value \\
\hline Age (years) & $1.02(0.99-1.06)$ & 0.192 & $1.03(0.99-1.07)$ & 0.104 \\
\hline \multicolumn{5}{|l|}{ Sex } \\
\hline Male & 1 (reference) & & 1 (reference) & \\
\hline Female & $2.19(1.25-3.82)^{\pi}$ & $0.006^{\pi}$ & $2.11(1.20-3.72)^{\pi}$ & $0.010^{\pi}$ \\
\hline \multicolumn{5}{|l|}{ Education level } \\
\hline$\geq 7$ years & 1 (reference) & & 1 (reference) & \\
\hline $0-6$ years & $2.44(1.41-4.22)^{\pi}$ & $0.001^{\pi}$ & $2.43(1.39-4.22)^{\pi}$ & $0.002^{\pi}$ \\
\hline \multicolumn{5}{|l|}{ Perceived economic status } \\
\hline Fair & 1 (reference) & & 1 (reference) & \\
\hline Poor & $1.57(0.96-2.57)$ & 0.071 & $1.65(1.00-2.71)$ & 0.050 \\
\hline \multicolumn{5}{|l|}{ Marital status } \\
\hline Married & 1 (reference) & & 1 (reference) & \\
\hline Unmarried/divorced/widowed & $1.33(0.79-2.25)$ & 0.283 & $1.40(0.82-2.38)$ & 0.216 \\
\hline \multicolumn{5}{|l|}{ Current smoking } \\
\hline No & 1 (reference) & & 1 (reference) & \\
\hline Yes & $2.26(1.06-4.81)^{\pi}$ & $0.034^{\pi}$ & $2.16(1.00-4.69)$ & 0.051 \\
\hline \multicolumn{5}{|l|}{ Alcohol drinking $\geq 1 /$ week } \\
\hline No & 1 (reference) & & 1 (reference) & \\
\hline Yes & $0.78(0.41-1.49)$ & 0.457 & $0.73(0.38-1.41)$ & 0.349 \\
\hline \multicolumn{5}{|l|}{ Difficulty of access to medical services } \\
\hline No & 1 (reference) & & 1 (reference) & \\
\hline Yes & $0.88(0.38-2.05)$ & 0.773 & $0.96(0.41-2.26)$ & 0.919 \\
\hline \multicolumn{5}{|l|}{ Number of chronic diseases ${ }^{\dagger}$} \\
\hline $0-1$ & 1 (reference) & & 1 (reference) & \\
\hline $2-3$ & $2.21(1.40-3.49)^{\pi}$ & $0.001^{\pi}$ & $2.19(1.38-3.46)^{\pi}$ & $0.001^{\pi}$ \\
\hline 4 or more & $2.06(1.03-4.13)^{\pi}$ & $0.042^{\pi}$ & $2.10(1.04-4.27)^{\pi}$ & $0.040^{\pi}$ \\
\hline \multicolumn{5}{|l|}{ Urination disorder ${ }^{\ddagger}$} \\
\hline No & 1 (reference) & & 1 (reference) & \\
\hline Yes & $1.06(0.61-1.84)$ & 0.827 & $1.08(0.62-1.88)$ & 0.784 \\
\hline \multicolumn{5}{|l|}{ Interference by pain } \\
\hline No & 1 (reference) & & 1 (reference) & \\
\hline Yes & $0.90(0.52-1.55)$ & 0.692 & $0.85(0.49-1.48)$ & 0.558 \\
\hline \multicolumn{5}{|l|}{ Depression $\S$} \\
\hline No & 1 (reference) & & 1 (reference) & \\
\hline Yes & $2.53(1.32-4.83)^{\pi}$ & $0.005^{\pi}$ & $2.38(1.23-4.57)^{\top}$ & $0.010^{\pi}$ \\
\hline \multicolumn{5}{|l|}{ Cognitive impairment" } \\
\hline No & 1 (reference) & & 1 (reference) & \\
\hline Yes & $0.83(0.49-1.40)$ & 0.473 & $0.89(0.52-1.53)$ & 0.684 \\
\hline \multicolumn{5}{|l|}{ Physical activity level } \\
\hline Moderate to high & 1 (reference) & & 1 (reference) & \\
\hline None to low & $0.81(0.49-1.34)$ & 0.416 & $0.88(0.52-1.47)$ & 0.613 \\
\hline Sleep duration (hours) & - & - & $0.81(0.70-0.94)^{\pi}$ & $0.004^{\pi}$ \\
\hline \multicolumn{5}{|l|}{ Snoring with apnea } \\
\hline No & - & & 1 (reference) & \\
\hline Yes & - & - & $1.40(0.58-3.36)$ & 0.456 \\
\hline
\end{tabular}

*adjusted for all the other variables in each column of the table, tincludes hypertension, diabetes mellitus, hyperlipidemia, arthritis, osteoporosis, cancer, stroke, myocardial infarction (or angina), tuberculosis, asthma, and hepatitis, *includes urinary incontinence and benign prostate hyperplasia, §defined by $\geq 10$ of the Geriatric Depression Scale-Short Form (15-item) scores, "defined by $\leq 23$ of the Mini-Mental State Examination scores, "significant OR. OR: odds ratio, CI: confidence interval 
could affect the other variables. Because marked sex differences were found in previous studies of our KSHAP sample, ${ }^{24-28}$ we evaluated interaction effects between sex and all other variables by adding interaction terms into the regression model to maximize the number of independent variables.

Data analyses were conducted using SPSS for Windows version 20 (SPSS Inc., Chicago, IL, USA), and statistical significance was set at $\mathrm{p}<0.05$.

\section{RESULTS}

Of the 509 participants, $32.4 \%(\mathrm{n}=165)$ had insomnia. Table 1 shows the socio-demographic, behavioral, and clinical characteristics of the participants. Compared with participants without insomnia, those with insomnia were older and had shorter sleep durations. Elderly participants with insomnia were more likely to be female, less educated, less likely to be married, and less frequent $(<1 /$ week $)$ alcohol drinkers. Participants with insomnia also had a greater number of chronic diseases and higher prevalence of depression.

To identify factors associated with insomnia, all variables were examined by multiple logistic regression analyses (Table 2). In model 1 , which excluded sleep duration and snoring with apnea, the following variables were positively associated with insomnia: female sex, low education level, current smoking, two or more chronic diseases, and depression. In model 2, which controlled for sleep duration and snoring with apnea, all of these factors, except for smoking, remained significantly associated with insomnia. Shorter sleep duration was also associated with insomnia in model 2 .

We found no significant interactions between sex and any other variables (data not shown).

\section{DISCUSSION}

We investigated factors associated with insomnia among Korean rural older adults. In this KSHAP community sample, we found that socio-demographic (sex, education level), behavioral (smoking), and clinical (number of chronic diseases, depression, and sleep duration) characteristics were associated with insomnia. This study is valuable in terms of exploring multidomain correlates of insomnia, including sleep-related factors, among rural community-dwelling older adults in Korea.

Aging perse is known to affect sleep architecture. Older adults often have difficulty of falling asleep or experience midsleep awakening, and their sleep efficiencies become reduced compared with those of younger adults. ${ }^{29}$ For this reason, the prevalence and severity of insomnia increase with age. ${ }^{30}$ Likewise, we found that participants in the insomnia group had a higher mean age than participants in the no insomnia group.
However, the association between age and insomnia disappeared after adjusting for other socio-demographic, behavior$\mathrm{al}$, and clinical factors in our multivariate analyses. This result is in line with an earlier epidemiological study ${ }^{31}$ that showed no association between age and sleep complaints after adjusting for the health status of elderly individuals. These observations suggest that the effect of age on insomnia could be mediated by age-related changes in sleep architecture and other aging-related factors such as chronic illness or depression.

Depression has repeatedly been found to be associated with insomnia in older adults. ${ }^{5,32}$ Depression and insomnia are independent risk factors for each other. ${ }^{33,34}$ The diagnosis and treatment of depression are essential for individuals with insomnia who do not recognize their depressive symptoms. Among the 57 participants considered to have depression in our sample, only five were diagnosed with depression by a doctor. As the prevalence of depression among the Korean elderly is estimated to be $30-40 \%,{ }^{22,35}$ the prevalence of depression in this study could be underestimated. Although the number of medical services in rural areas is far less than that in the urban areas, ${ }^{36}$ this potential under-diagnosis of depression in our cohort does not seem be a result of "difficulty" in access to medical services, as over $90 \%$ of participants did not report difficulty in accessing medical services. Because the main objective of the second wave of the KSHAP project was not to perform psychiatric/behavioral evaluations, the plan for the next wave of the KSHAP study should include psychiatric interviews and assessment of medical service utilization, so that we can better understand the relationship between insomnia and depression.

Female sex and low educational level were also associated with insomnia, consistent with previous studies. ${ }^{5,32}$ Female sex and low educational level are also risk factors for poor health and chronic illness. ${ }^{37}$ According to Cutler and Lleras-Muney, ${ }^{38}$ education is associated with general health of population via income, access to healthcare, problem solving skills, social network, and relative social position. Among all of the clinical factors, we found that only the number of chronic diseases was a significant correlate of insomnia. By contrast, pain was the predominant associative factor of insomnia in other Asian studies. ${ }^{39,40}$ This difference between studies might be due to the fact that we examined interference by pain instead of the mere presence of pain. Based on these findings, we plan to conduct a follow-up study to investigate the effect of targeted intervention programs on insomnia among high-risk groups.

There were some limitations to our study. First, all examined variables were based on subjective reports by participants. Second, this study employed a cross-sectional design, so we were unable to determine causal relationships. Third, medication use was not included in our analyses. Fourth, we did 
not include anxiety symptoms that could be additional psychological factors influencing insomnia. However, a strength of this study is that we collected a complete dataset (i.e., no missing data) using well-trained interviewers. Moreover, this study reflects a real community situation by investigating multiple factors affecting the health of elderly individuals.

In conclusion, we found that sex, education, chronic disease, and depression independently increase the risk of insomnia among older adults in a Korean rural community. These findings suggest the need to manage insomnia and its correlates in rural older adults by considering socio-demographic, behavioral, and clinical characteristics. It will also be necessary to perform proper interventions targeting underdiagnosed and under treated modifiable factors such as depression. Our results can be useful for establishing prevention policies for insomnia among aged populations.

\section{Acknowledgments}

This study was supported by grants from the National Research Foundation of Korea funded by the Korean Government (NRF-2014S1A3A204496) and the Korean Mental Health Technology R\&D Project, Ministry of Health \& Welfare (HM15C0995), Republic of Korea.

\section{REFERENCES}

1. World Health Organization. Active Ageing. A policy Framework. Geneva: World Health Organization; 2002;1-60. Available at: http://apps. who.int/iris/bitstream/10665/67215/1/WHO_NMH_NPH_02.8.pdf. Accessed January 4, 2016.

2. Statistics Korea. Future Population Estimation: 2010-2060. Daejeon: Statistics Korea; 2011. Available at: http://kostat.go.kr. Accessed January 4, 2016.

3. Health Insurance Policy Research Institute. Increase in sleep disorder. Wonju: National Health Insurance Service; 2015. Available at: http://www. korea.kr/common/download.do?fileId=184085355\&tblKey=GMN. Accessed January 4, 2016.

4. Ancoli-Israel S. Normal Human Sleep at Different Ages: Sleep in the Older Adult. In: Sleep Research Society, Editors. SRS Basics of Sleep Guide. Westchester, IL: Sleep Research Society, 2005, p.21-26.

5. Ohayon MM. Epidemiology of insomnia: what we know and what we still need to learn. Sleep Med Rev 2002;6:97-111.

6. Lee E, Cho HJ, Olmstead R, Levin MJ, Oxman MN, Irwin MR. Persistent sleep disturbance: a risk factor for recurrent depression in community-dwelling older adults. Sleep 2013;36:1685-1691.

7. Mallon L, Broman JE, Hetta J. Relationship between insomnia, depression, and mortality: a 12-year follow-up of older adults in the community. Int Psychogeriatr 2000;12:295-306.

8. Stone KL, Blackwell TL, Ancoli-Israel S, Cauley JA, Redline S, Marshall LM, et al. Sleep disturbances and risk of falls in older communitydwelling men: the outcomes of Sleep Disorders in Older Men (MrOS Sleep) Study. J Am Geriatr Soc 2014;62:299-305.

9. Lee M, Choh A, Demerath E, Knutson K, Duren D, Sherwood R, et al. Sleep disturbance in relation to health-related quality of life in adults: the Fels Longitudinal Study. J Nutr Health Aging 2009;13:576-583.

10. Carroll JE, Seeman TE, Olmstead R, Melendez G, Sadakane R, Bootzin $\mathrm{R}$, et al. Improved sleep quality in older adults with insomnia reduces biomarkers of disease risk: pilot results from a randomized controlled comparative efficacy trial. Psychoneuroendocrinology 2015;55:184-192.

11. Yang CK, Yoo SY, Joo YH, Hahn HM. Sleep habits and sleep disorders among the elderly between 65-84 years who are living in a part of $\mathrm{Pu}$ - san. Sleep Med Pscyhophysiol 1997;4:66-76.

12. Yoon JS, Shin IS, Kim JM, Kang SA, Ha HY, Park IS, et al. Sleep patterns and problems of the korean elderly in urban and rural areas. Korean J Sleep Med 1999;1:42-49.

13. Hong JP, Ahn JH, Yun YK, Park JI, Lee SY, Hahm BJ, et al. Sleep habits and insomnia-associated factors in the urban elderly: demographic, health and psychobehavioral correlates. J Korean Neuropsychiatr Assoc 2000;39:1111-1121.

14. Kim JM, Stewart R, Kim SW, Yang SJ, Shin IS, Yoon JS. Insomnia, depression, and physical disorders in late life: a 2-year longitudinal community study in Koreans. Sleep 2009;32:1221-1228.

15. Kwon SM, Seo JS, Yang SK, Choi JY, Yim HW, Jo SJ, et al. A field study of the conditions of the elderly in rural community: the correlation between of sleep quality and quality of life. J Korean Neuropsychiatr Assoc 2012;51:119-126.

16. Yang HC, Suh S, Kim H, Cho ER, Lee SK, Shin C. Testing bidirectional relationships between marital quality and sleep disturbances: a 4-year follow-up study in a Korean cohort. J Psychosom Res 2013;74:401-406.

17. Chang KJ, Son SJ, Lee Y, Back JH, Lee KS, Lee SJ, et al. Perceived sleep quality is associated with depression in a Korean elderly population. Arch Gerontol Geriatr 2014;59:468-473.

18. Carvalho FG, Hidalgo MP, Levandovski R. Differences in circadian patterns between rural and urban populations: an epidemiological study in countryside. Chronobiol Int 2014;31:442-449.

19. Cho HJ. Equity in health care: current situation in South Korea. J Korean Med Assoc 2013;56:184-194.

20. Lee JM, Lee WJ, Kim HC, Choi W, Lee J, Sung K, et al. The Korean social life, health and aging project-health examination cohort. Epidemiol Health 2014;36:e2014003.

21. Maruish ME, Turner-Bowker DM. A Guide to the Development of Certified Modes of Short Form Survey Administration. Lincoln, RI: QualityMetric Incorporated; 2009.

22. Bae JN, Cho MJ. Development of the Korean version of the Geriatric Depression Scale and its short form among elderly psychiatric patients. J Psychosom Res 2004;57:297-305.

23. Kim TH, Jhoo JH, Park JH, Kim JL, Ryu SH, Moon SW, et al. Korean version of mini mental status examination for dementia screening and its' short form. Psychiatry Investig 2010;7:102-108.

24. Lee WJ, Youm Y, Rhee Y, Park YR, Chu SH, Kim HC. Social network characteristics and body mass index in an elderly Korean population. J Prev Med Public Health 2013;46:336-345.

25. Lee SW, Youm Y, Kim CO, Lee WJ, Choi W, Chu SH, et al. Association between skeletal muscle mass and radial augmentation index in an elderly Korean population. Arch Gerontol Geriatr 2014;59:49-55.

26. Lee SW, Youm Y, Lee WJ, Choi W, Chu SH, Park YR, et al. Appendicular skeletal muscle mass and insulin resistance in an elderly Korean population: the Korean social life, health and ageing project-health examination cohort. Diabetes Metab J 2015;39:37-45.

27. Chu SH, Baek JW, Kim ES, Stefani KM, Lee WJ, Park YR, et al. Gender differences in hypertension control among older Korean adults: Korean social life, health, and ageing project. J Prev Med Public Health 2015; 48:38-47.

28. Song BM, Lee JM, Choi W, Youm Y, Chu SH, Park YR, et al. Association between $\mathrm{C}$ reactive protein level and depressive symptoms in an elderly Korean population: Korean Social Life, Health and Ageing Project. BMJ Open 2015;5:e006429.

29. Li J, Yao YS, Dong Q, Dong YH, Liu JJ, Yang LS, et al. Characterization and factors associated with sleep quality among rural elderly in China. Arch Gerontol Geriatr 2013;56:237-243.

30. Weyerer S, Dilling H. Prevalence and treatment of insomnia in the community: results from the Upper Bavarian Field Study. Sleep 1991;14:392398.

31. Foley DJ, Monjan AA, Brown SL, Simonsick EM. Sleep complaints among elderly persons: an epidemiologic study of three communities. Sleep1995;18:425-432. 
32. Smagula SF, Stone KL, Fabio A, Cauley JA. Risk factors for sleep disturbances in older adults: evidence from prospective studies. Sleep Med Rev 2016;25:21-30.

33. Chang PP, Ford DE, Mead LA, Cooper-Patrick L, Klag MJ. Insomnia in young men and subsequent depression. The Johns Hopkins Precursors Study. Am J Epidemiol 1997;146:105-114.

34. Katz DA, McHorney CA. Clinical correlates of insomnia in patients with chronic illness. Arch Intern Med 1998;158:1099-1107.

35. Cho MJ, Nam JJ, Suh GH. Prevalence of symptoms of depression in a nationwide sample of Korean adults. Psychiatry Res 1998;81:341-352.

36. District office of Ganghwa-gun. Current situation of Medical institutions. 2014 Annual Statistical Report. Ganghwa: Ganghwa-gun District; 2015. Available at: http://www.ganghwa.go.kr/open_content/ main/ganghwa/info/general_medical.jsp. Accessed February 1, 2016.

37. Woo EK, Han C, Jo SA, Park MK, Kim S, Kim E, et al. Morbidity and related factors among elderly people in South Korea: results from the Ansan Geriatric (AGE) cohort study. BMC Public Health 2007;7:10.

38. Cutler DM, Lleras-Muney A. Education and Health: Evaluating Theories and Evidence. National Poverty Center Working Paper Series. Cambridge, MA: National Bureau of Economic Research; 2006.

39. Su TP, Huang SR, Chou P. Prevalence and risk factors of insomnia in community-dwelling Chinese elderly: a Taiwanese urban area survey. Aust N Z J Psychiatry 2004;38:706-713.

40. Ito Y, Tamakoshi A, Yamaki K, Wakai K, Kawamura T, Takagi K, et al. Sleep disturbance and its correlates among elderly Japanese. Arch Gerontol Geriatr 2000;30:85-100. 